\title{
Cleidocranial Dysplasia
}

National Cancer Institute

\section{Source}

National Cancer Institute. Cleidocranial Dysplasia. NCI Thesaurus. Code C75020.

A rare autosomal dominant disorder caused by mutations in the RUNX2 gene. It is characterized by developmental abnormalities in the bones and teeth, including the complete or partial absence of the clavicles, delayed closure of the fontanels, protruding mandible, hypertelorism, scoliosis, and short stature. 